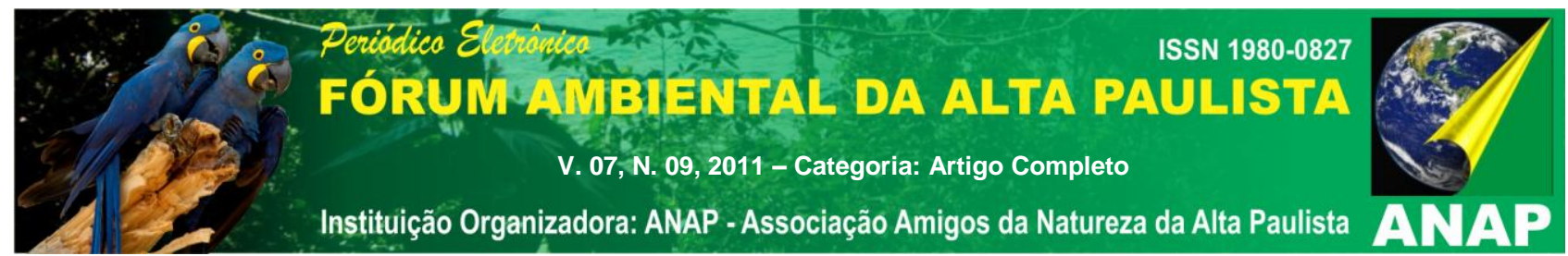

\title{
ESTUDO SOBRE O KANGINGIN REVELA RELAÇÕES HISTÓRICAS ENTRE HOMENS E NATUREZA
}

\author{
Marcelo Franco Leão ${ }^{1}$
}

RESUMO: Este artigo apresenta resultados do estudo realizado durante as aulas de Química sobre um licor genuinamente mato-grossense que envolveu os temas transversais Diversidade Cultural e Educação Ambiental. O estudo objetivou investigar a composição química da bebida Kangingin, evidenciar sua importância enquanto contribuição da cultura afro-brasileira e valorizar a relação histórica existente entre os homens e a rica flora existente em Mato Grosso. A metodologia adotada foi a da pesquisa de campo realizada em Vila Bela da Santíssima Trindade - MT. O grupo envolvido na pesquisa foi composto por alunos do Centro de Educação de Jovens e Adultos 15 de Outubro, de Barra do Bugres - MT. Justifica-se a aplicação do mesmo para corresponder às curiosidades da comunidade escolar em descobrir os benefícios trazidos à saúde por esse licor e o quanto o mesmo significa no contexto histórico do Estado, além de comprovar as propriedades afrodisíacas da bebida. A produção deste licor é artesanal, tem como ingredientes a cachaça, o mel e algumas plantas da flora brasileira e foi desenvolvida pelos descendentes de africanos trazidos para região na condição de escravos. Pela investigação dos ingredientes que foram revelados, notou-se que a reunião de tais substâncias apresenta inúmeras propriedades medicinais das quais se destacam as ações tônica, vasodilatadora e estimulante da circulação periférica, o que torna a bebida, além de afrodisíaca, um excelente energético. Os resultados trazidos pela pesquisa foram surpreendentes, pois essa é uma bebida de inúmeros valores não só nutritivos como também da cultura de um povo.

Palavras-chave: Kangingin. Química. Cultura mato-grossense.

\footnotetext{
${ }^{1}$ Marcelo Franco Leão - Mestrando em Psicanálise, Educação e Sociedade pelo INSET, especialista em Orientação Educacional pela Faculdade Dom Alberto, pós-graduando em Relações Raciais na Educação e na Sociedade Brasileira pela UFMT, graduado em Química e Física Licenciatura Plena pela UNISC e professor na UNEMAT - Campus de Barra do Bugres - MT, e-mail: marcelofrancoleao@yahoo.com.br
} 


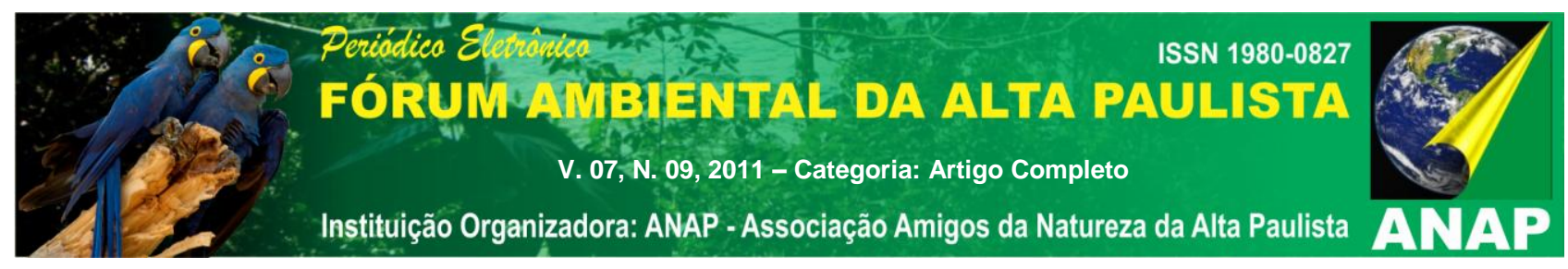

\section{INTRODUÇÃO}

Grande parte da população desconhece a Química, ou a consideram algo prejudicial ao meio ambiente e/ou às pessoas, o que é um equívoco. $O$ entendimento dessa ciência e sua prática contribuem para alcançarmos qualidade de vida. Compreender os fenômenos do cotidiano dá ao homem um maior domínio sobre a produção, seja de irrigação, agricultura, criação de animais e a metalurgia. A interpretação do mundo através das ferramentas da Química é essencial, porque explicita seu caráter dinâmico e sendo assim, ela deve ser colocada de forma clara relacionada ao meio em que vivemos. Segundo os Parâmetros Curriculares Nacionais, Brasil (2000), para haver relação entre conhecimento escolar e conhecimento popular, na educação em Química, é importantíssimo apresentar aos alunos fatos concretos, observáveis e mensuráveis, já que os conceitos que os alunos trazem para a sala de aula advêm de sua leitura de mundo.

Realizar intervenções pedagógicas viabiliza ao profissional da educação trabalhar de forma interdisciplinar por envolver conhecimentos científicos no universo das relações inter-pessoais que se estabelecem no ambiente escolar, conforme orienta os PCN's ao tratar da diversidade. Não é possível falar de diversidade na sociedade brasileira de forma descontextualizada, é preciso buscar, em fatos históricos, elementos que emergem deste contexto para assim entender o comportamento humano. Também é preciso que a sociedade brasileira reconheça a contribuição dos diferentes povos para a construção do país e uma das formas legítimas de se fazer o reconhecimento de tal contribuição é dar visibilidade a trajetória, as contribuições e heranças culturais dos mesmos.

Ao se tratar da trajetória de formação da sociedade brasileira, a história ensinada, segundo estudos de Brito (2011), era a de que três povos a constituíam e que esse encontro era pacífico, reconheciam a participação do povo africano e indígena, mas evidenciavam o povo europeu como condutor e fundador dessa nação. Essa concepção 


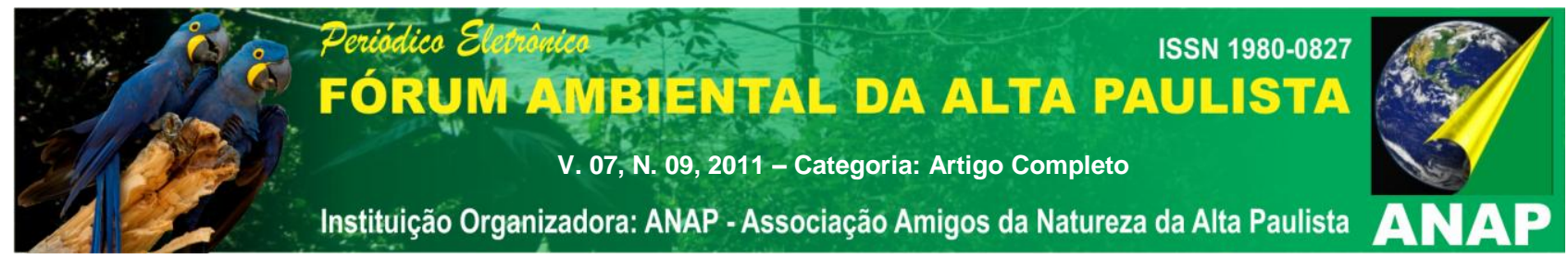

foi justificada pela elite associando o povo negro ao comportamento bárbaro, o que requeria o regime de escravidão, também aferiu ao povo indígena um comportamento indócil ou não adaptado, mas ao europeu como sendo superior e civilizado, um exemplo a ser seguido e almejado, o que não corresponde a verdade, porém está incutido no imaginário social.

A escravidão deixou os africanos, trazidos pelo tráfico dos navios negreiros, bem como seus descendentes escravizados, seres praticamente sem autonomia, vontade própria e capacidade de reação, tirando assim do escravo o status de humano, transformando-o em coisa. No entanto, mesmo em condições adversas esse segmento resistiu de diversas maneiras para conquistar a liberdade e preservar sua cultura. As diferentes etnias trazidas da África trouxeram consigo a diversidade de uma cultura rica que foi socializada na formação das famílias, na vida social e na religiosidade do povo negro. Os grupos étnicos tentaram manter vínculos por identificação e pertencimento nas cidades onde viviam.

Nos estudos de Ferreira (2001), o crescimento de Vila Bela foi gradativo após sua instituição como capital em 1751 e teve como fator de sua composição étnica, os negros oriundos da África para o trabalho escravo, além dos migrantes brancos das diversas áreas da Colônia. Conforme descreve os Anais de Vila Bela ${ }^{2}$, desde os primórdios, a colonização daquela cidade e arredores foi branca e negra, pois é impressionante o registro do número e da importância relativa dos negros em todas as atividades desenvolvidas, das econômicas às religiosas, das culturais às militares, das sociais às religiosas. Esse documento descreve também sobre os negros que se rebelavam contra a escravidão, negros fugidos e quilombolas.

A resistência à escravidão foi outro aspecto, segundo Brito (2011), mal contado na história que conhecemos. Nem sempre o povo negro foi passivo, por longos anos ele lutou e ansiou por liberdade. Até o ato de empreender fuga não era uma ação impensada,

\footnotetext{
${ }^{2}$ Documento que retrata os acontecimentos da cidade de Vila Bela da Santíssima Trindade - MT entre os anos entre 1734 a 1789.
} 


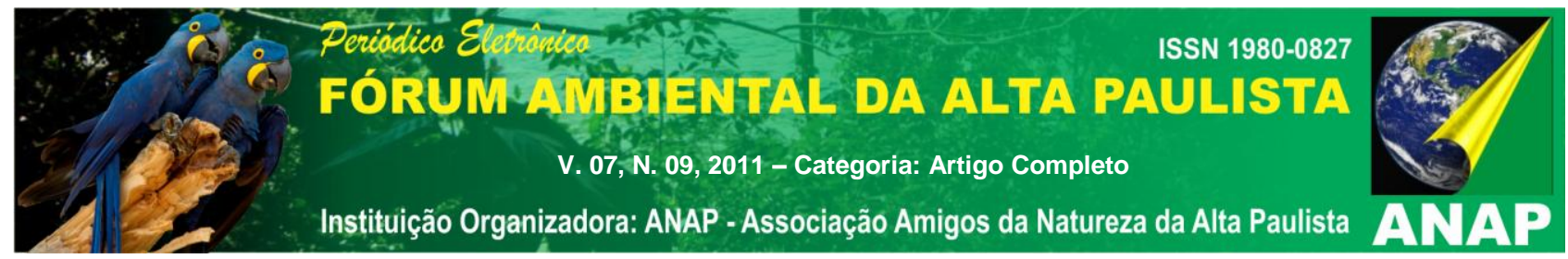

mas sim uma ação planejada que poderia não ser definitiva. O quilombo foi outra maneira de resistir que surgiu da necessidade de abrigar aos negros fugitivos. Ainda pelos estudos do autor, as comunidades quilombolas eram estruturadas e que não viviam somente negros fugitivos. Em alguns deles havia índios e até mesmo brancos pobres. As revoltas e insurreições ocorreram por todo o Brasil e muito pouco se conhece delas, porém sabe-se que ansiavam liberdade e/ou condições de trabalho digno e melhores condições de vida.

Segundo os estudos de Santos (2010), os africanos trouxeram diferentes tradições culturais e certamente fizeram trocas culturais entre si, conforme seus grupos de origem, para criar aqui uma cultura afro-brasileira. Neste período escravocrata, o negro reelabora os elementos da cultura trazida consigo, dentro das condições possíveis por estar num contexto adverso. Assim, surgem então inúmeras contribuições ao patrimônio intelectual, cultural e científico do povo brasileiro, e foi durante o período de escravidão, na senzala, que surgiu o licor Kangingin de Vila Bela da Santíssima Trindade $-\mathrm{MT}^{3}$, de acordo com os Anais daquele município.

Os estudos de Silva Filho (2010) apontam que geralmente são listadas como heranças culturais africanas o samba como música e dança, a capoeira como arte marcial, o candomblé como religião, a feijoada e outras comidas baianas como culinária. $\mathrm{Na}$ verdade, também é preciso mencionar, segundo o autor, que outras significativas contribuições culturais foram deixadas como o andar bamboleante, o gingado, a espontaneidade nos gestos e no falar, o riso largo e farto, o gosto pelas cores vivas, alegres, vistosas das vestimentas, a música ritmada, os instrumentos de percussão, as comidas picantes, gordurosas e afrodisíacas são contribuições africanas na cultura brasileira. Em comunhão com os apontamentos do referido autor, é importante registrar que, nesse universo cultural, as bebidas também se constituem como herança africana para a sociedade brasileira, sendo o Kangingin de Vila Bela da Santíssima Trindade, bebida de grande apreço devido a ser genuinamente mato-grossense.

\footnotetext{
${ }^{3}$ Vila Bela da Santíssima Trindade foi a primeira capital da província de Mato Grosso, fica distante de Cuiabá $525 \mathrm{~km}$ e tem uma população atual de 13.886 hab.
} 


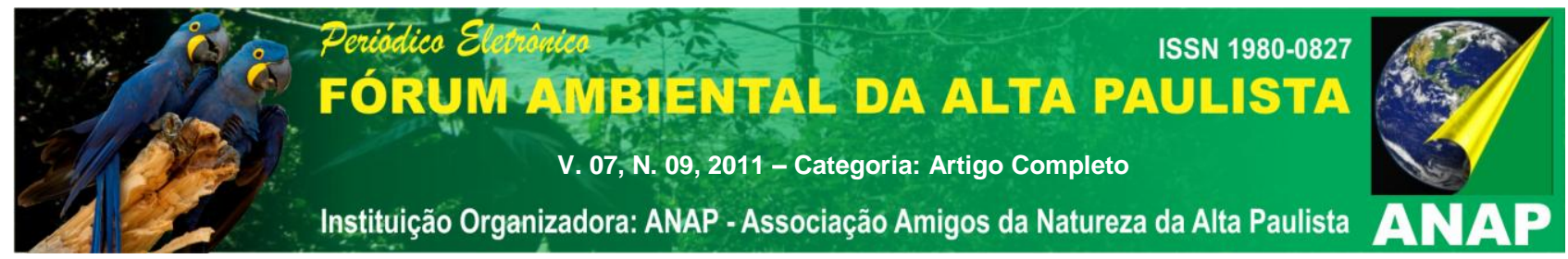

O reconhecimento da herança cultural africana e o valor do ser negro na sociedade brasileira devem constituir-se em todas as esferas sociais e fundamentalmente nos espaços educativos. Cabe, então, as instituições educativas desenvolverem práticas em todas as áreas do conhecimento, que possibilitem uma educação multicultural e valorize o local em que se vive e realizem práticas que constituam o aluno como um agente transformador da realidade, desempenhando assim o seu papel, segundo o pensamento de Bandeira e Freire (2006).

Conforme os Parâmetros Curriculares Nacionais, Brasil (2000), o aprendizado de Química implica na compreensão das transformações e das reações químicas que ocorrem no meio ambiente, de forma que os alunos possam comparar as informações obtidas com sua própria cultura e com a mídia, tomando decisões enquanto indivíduos e cidadãos.

O interesse na pesquisa, então, surgiu à partir dos estudos teóricos de fatos históricos do Estado associados a área de Química, bem como da curiosidade da comunidade escolar em conhecer os aspectos químicos do Kangingin enquanto bebida, evidenciar sua importância enquanto contribuição da cultura afro-brasileira e valorizar a relação histórica existente entre os homens e a rica flora existente em Mato Grosso.

\section{MATERIAIS E MÉTODOS}

Como métodos utilizados na pesquisa, a revisão de literatura foi imprescindível para embasar o estudo e executar o projeto. O uso de computadores e da internet se fizeram necessários por serem maneiras eficazes para buscar um entendimento maior do conteúdo levantado, até mesmo por existir pouca bibliografia sobre o assunto. A pesquisa de campo também foi necessária pelo fato de levantar dados históricos, propriedades e formas de preparo desse licor africano de grande apreço cultural devido ser genuinamente mato-grossense. 


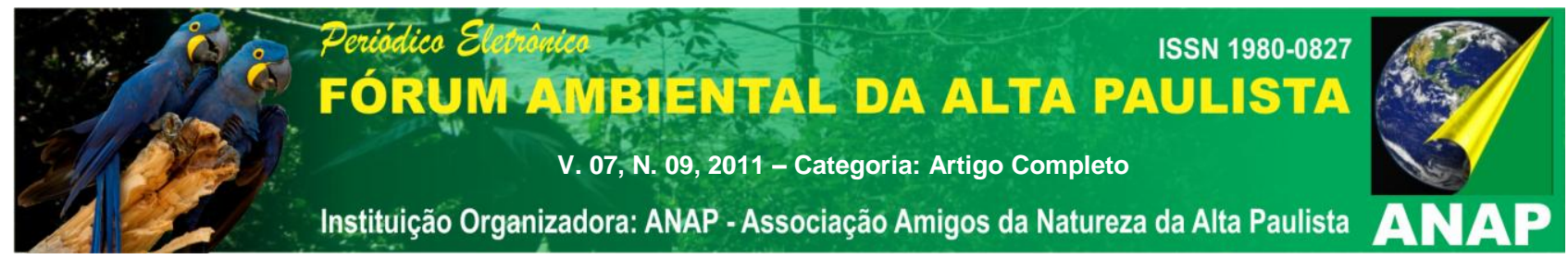

O projeto foi executado no Centro de Educação de Jovens e Adultos, CEJA "15 de Outubro", com os alunos das turmas ID e IIIB do Ensino Médio noturno e foi desenvolvido durante as aulas de Química, bem como nas oficinas pedagógicas da área de Ciências Naturais, Matemática e suas tecnologias, numa ação interdisciplinar, no decorrer do último trimestre do ano de 2010. Após executado com esses alunos, o mesmo foi estendido para toda a escola, bem como para a sociedade barrabugrense através da divulgação dos resultados.

Os instrumentos de coleta de dados para a realização deste trabalho foram a observação dos participantes; os fatos históricos ocorridos no Estado; às visitas de campo especialmente à Vila Bela da Santíssima Trindade; os relatos e depoimentos dos moradores daquela comunidade; a análise dos ingredientes deste licor; e a divulgação de resultados através da mídia, a fim de expandir os conhecimentos adquiridos. Ressalva-se que a investigação teve como ponto de partida os conhecimentos da área de Química associada às demais áreas do conhecimento, bem como com as discussões em torno do meio ambiente e sua influência nas interações sociais, de forma a conseguir interpretar com eficácia a temática proposta.

\section{RESULTADOS E DISCUSSÕES}

A bebida Kangingin foi apresentada aos sujeitos da pesquisa como afrodisíaca e esse fato despertou a curiosidade deles em saber quais motivos assim a tornavam. Para que esse questionamento fosse sanado, propôs-se desenvolver este trabalho a fim de analisar e apontar as contribuições nutricionais, histórica e cultural deixadas por esse licor de origem africana ao Estado de Mato Grosso.

Durante as idas a campo, foram proporcionados momentos para que alunos pudessem ouvir depoimentos de pessoas que residem em Vila Bela da Santíssima sobre a história do Kangingin, o preparo do licor e o que este representa para a cultura da cidade. Nesse ínterim, foram observadas as inúmeras contribuições culturais trazidas pelos afro-descendentes desde a formação da sociedade mato-grossense. 


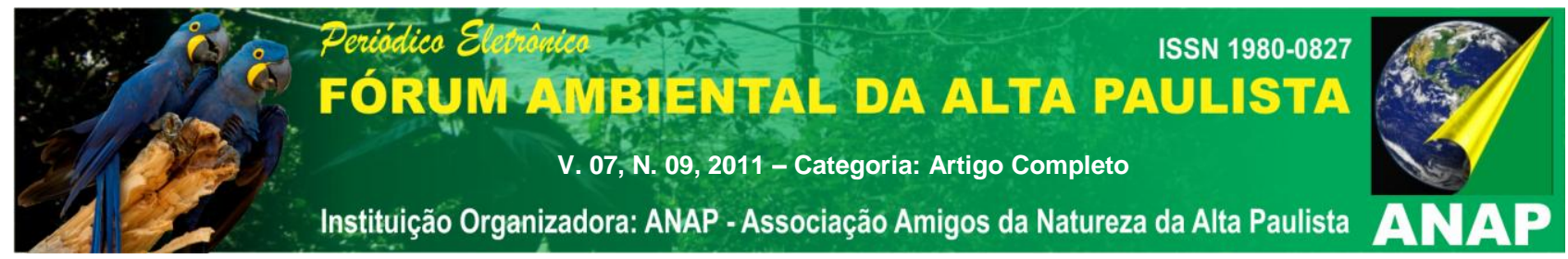

Pelas entrevistas, foi possível saber que o licor Kangingin é composto pelos seguintes ingredientes: cachaça, mel, canela, erva-doce, gengibre, cravo-da-índia e um ingrediente secreto. Cada um desses ingredientes, entre eles ervas e raízes, foram investigados na literatura e na internet na tentativa de descobrir, através das características de composição, os benefícios medicinais, os componentes afrodisíacos e as contribuições nutricionais provocadas pelo licor ao corpo humano.

Dentre os depoimentos revelados por moradores vilabelenses, merece destaque o da Sra. M. S. F., de 57 anos, quando questionada da forma de preparar o licor revela alguns ingredientes da bebida e o cuidado em preservar esta tradição:

O jeito de fazer é bem simples, tudo começa quando esquentamos a água e colocamos pra ferver o gengibre, as cascas de canela, os cravinhos e também a erva doce. Logo depois botamos o mel e por último é a cachaça. Tem um ingrediente secreto que utilizamos no preparo, mas isso é um segredo que só as pessoas de nossa tradição e de nossa raça podem saber.

Segundo o Portal do Colégio São Francisco (2010), a cachaça contém etanol entre $38 \%$ e $54 \%$ em volume, a $20^{\circ} \mathrm{C}$, obtida através da destilação do caldo de cana-de-açúcar fermentado e seu uso é suplementar e circunstancial ao consumo generalizado de uma bebida alcoólica, que inebria, sublima, liberta, embriaga, entorpece, dá prazer. Remedia, salva, alegra,deprime, habitua, vicia e mata, de acordo com a qualidade, a quantidade e a freqüência na qual é ingerida.

Sobre a composição química do mel, foi descoberto que são mais de 70 substâncias diferentes que o compõe, entre as quais figuram enzimas, aminoácidos, hidratos de carbono, vitaminas A, B1, B2, B5, C e os sais minerais mais importantes, como o potássio, o fósforo, o cálcio, o sódio, o ferro, cobre e o manganês. Como propriedades medicinais, destaca-se o poder de nutrir, prevenir doenças, dar mais energia, mais vivacidade, mais capacidade física e intelectual, além de ajudar a beleza da pele.

Segundo o catálogo rural da AGROV (2010), o gengibre apresenta em sua composição química: Gingerol, zingibereno, beta-bisaboleno, zingerona, citrol, canfeno, 


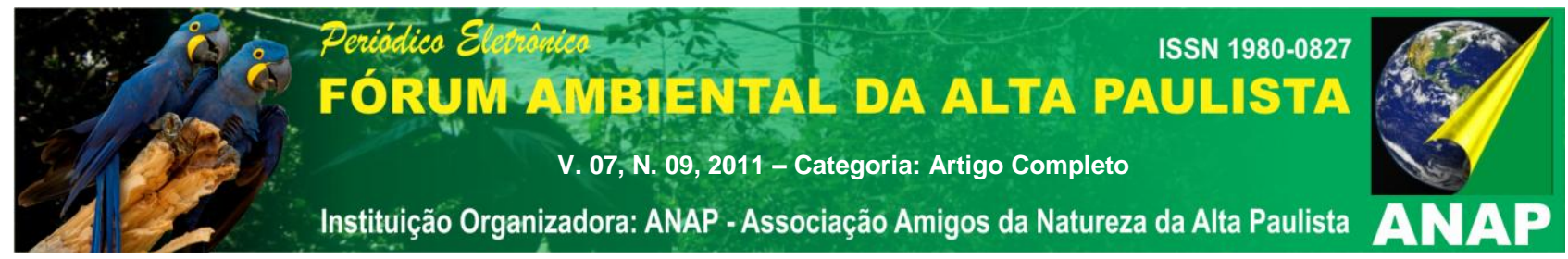

cineol, a-felandreno, saponinas e borneol. Como propriedades medicinais ele é classificado como antisséptico, antiemético, antiinflamatório, bacteriostática, carminativo, espasmolítico, estimulante da circulação periférica e estomáquico.

A canela, segundo o Portal do Colégio São Francisco (2010), apresenta em sua composição química: Acetato de eugenol, ácido cinâmico, açúcares, aldeído benzênico, aldeído cinâmico, aldeído cumínico, benzonato de benzil, cimeno, cineol, elegeno, eugenol, felandreno, furol, goma, linalol, metilacetona, mucilagem, oxalato de cálcio, pineno, resina, sacarose, tanino e vanilina e como características medicinais o poder de ser adstringente, afrodisíaca, anti-séptica, aperiente, aromática, carminativa, digestiva, estimulante, hipertensora, sedativa, tônica e vasodilatadora.

O cravo-da-índia tem como compostos químicos o eugenol, acetato de eugenol, beta-cariofileno, ácido oleânico, triterpeno, benzaldeído, ceras vegetais, cetona, chavicol, resinas, taninos, ácido gálico e esteróis, fazendo com que seja antiinflamatório, cicatrizante, analgésico, anticéptico e eficaz na eliminação de bactérias presentes na boca.

A erva doce, segundo a Revista Ervas \& Saúde (1998), contém anetol, proteínas, óleo fixo, açúcares e cumarinas. Suas propriedades medicinais atuam nas constipações estomacais e intestinais, dismenorréias, dores de hérnia, cólicas, afecções das vias urinárias, impigem, cansaço oftálmico, diarréias fétidas, azia e olhos inflamados.

Confrontando as informações trazidas pelos dados da Revista Erva \& Saúde, do Portal do Colégio São Francisco e do Catálogo Rural da AGROV, constatou-se que nos ingredientes investigados, os principais componentes químicos são o etanol encontrado na cachaça, os aminoácidos, sacarose, vitaminas $A, B_{1}, B_{2}, B_{5}, C$ e sais minerais identificados no mel, o eugenol da canela e do cravo-da-índia, o anetol e proteínas encontradas na erva-doce e o gingerol observado no gengibre.

Assim, o teor alcoólico da bebida estudada é de aproximadamente $30 \%$ e devido conter esses ingredientes. Ele apresenta várias propriedades medicinais das quais se destacam as ações tônica, vasodilatadora e estimulante da circulação periférica o que 


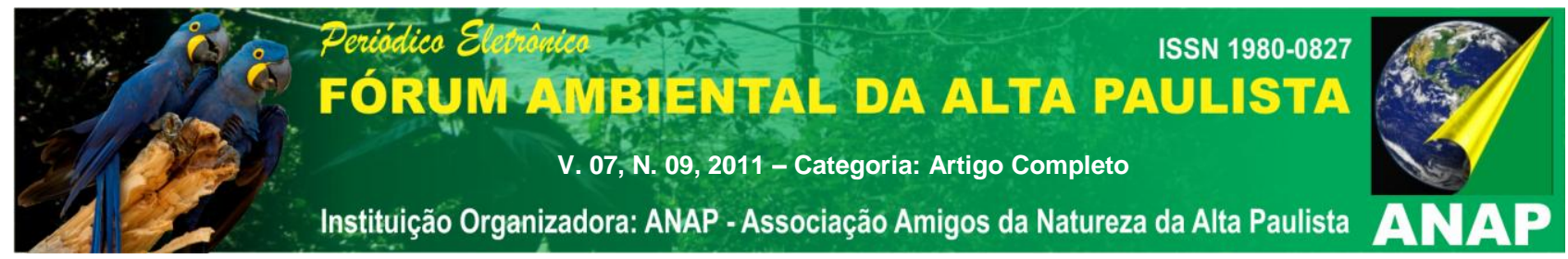

torna a bebida, além de afrodisíaca, um excelente energético. Isso só é possível devido à reunião dessas substâncias que o compõem.

$\mathrm{Na}$ escola, foram realizadas aulas práticas para preparação do licor Kangingin durante as oficinas pedagógicas que a modalidade oferece. A utilização do material concreto possibilitou obter maior conhecimento do licor, além de ser uma forma atrativa para ocorrer $\mathrm{o}$ aprendizado. Também foram confeccionados rótulos para a bebida representando a imagem das ruínas da Igreja Matriz de Vila Bela da Santíssima Trindade ${ }^{4}$, templo esse considerado patrimônio cultural, na intenção de divulgar a pesquisa que aponta a edificação como obra do trabalho escravo no período colonial.

Pela pesquisa teórica e pelos depoimentos foi possível verificar a contribuição histórica desse licor para o Estado de Mato Grosso, uma vez que continua sendo produzido, cultivado e servido durante as comemorações da Festa do Congo ${ }^{5}$, realizado em Vila Bela da Santíssima Trindade, evidenciando, dessa forma, o orgulho de um povo em conservar tradições e heranças deixadas por seus antepassados africanos.

Conforme pontua Firmo (2010), as heranças culturais dos afro-descendentes brasileiros devem ser evidenciadas, tendo em vista o valor e as influências delas para a formação da sociedade brasileira conforme está composta hoje. Por isso existe a necessidade de espaços para manifestá-las e torná-las visíveis. Foi proposto então reverenciar tais heranças divulgando os resultados da pesquisa por meio de: preparo do Kangingin pelos alunos da fase I D do Ensino Médio do Ceja 15 de Outubro e degustação da bebida pela comunidade escolar durante o sábado cultural na referida escola, na culminância do projeto Mato Grosso, em que se resgataram as origens mato-grossenses; divulgação de fotos e depoimentos recebidos nos murais da escola e em slides apresentados durante a noite cultural; e divulgação de matéria na imprensa local,

\footnotetext{
${ }^{4}$ A Igreja Matriz da Santíssima Trindade, localizada em Vila Bela da Santíssima Trindade-MT, foi construída em 1771 por escravos.

${ }^{5}$ A festa do Congo é uma das tradições mais antigas do estado de Mato Grosso, que tem como guardião São Benedito e faz parte do calendário oficial da cidade de Vila Bela da Santíssima Trindade no mês de Julho.
} 


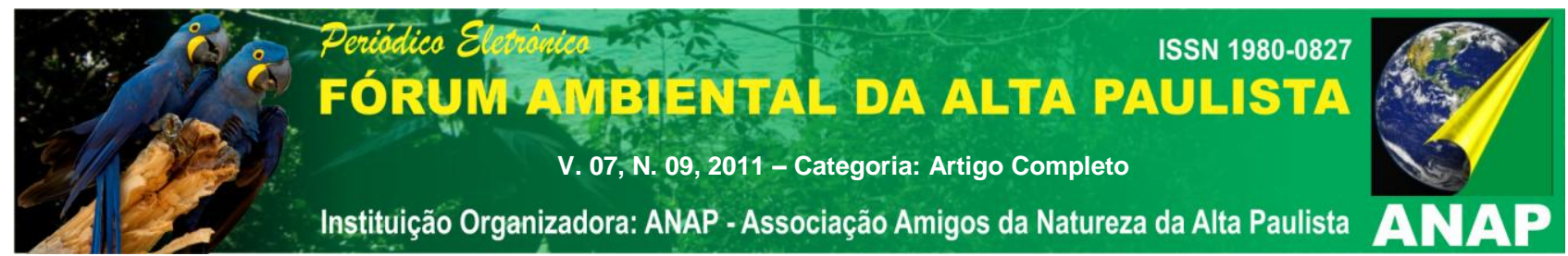

disponível no site: www.barra1.net e no site da mantenedora do educandário, SEDUC MT.

\section{CONCLUSÃO}

Os resultados trazidos por este trabalho foram surpreendentes, pois essa é uma bebida de inúmeros valores não só nutritivos como também da cultura de um povo. Pela investigação da composição química dos ingredientes foi possível perceber a riqueza da flora brasileira e conhecer algumas de suas propriedades medicinais. $O$ fato histórico da origem do Kangingin demonstra a antiga relação existente entre homem e natureza, uma vez que o primeiro é totalmente dependente do meio no qual está inserido, e evidencia a necessidade deste saber preservar, conhecer e utilizar os recursos que ainda dispõe com sabedoria.

Através da realização deste trabalho, foi proporcionado um ambiente mais envolvente e dinâmico para o aluno, o que o levou a desenvolver suas habilidades cognitivas e aprender de uma maneira diferente daquela tradicional passada em sala de aula. Possibilitou a ele prender novas técnicas que lhe despertaram o interesse, além de fazer com que a sala de aula ficassem mais descontraída e animada em meio as descobertas tão interessantes.

A valorização da biodiversidade, da história e da cultura mato-grossense através da pesquisa, permitiu aos envolvidos conhecer, respeitar e admirar o diferente. Compreender a importância da diversidade cultural possibilitou também refletir sobre o convívio social em Mato Grosso e o quanto ainda precisa-se avançar no quesito respeito às diferenças para estabelecer relações pacíficas e respeitosas nessa sociedade.

\section{REFERÊNCIAS}

AGROV Catálogo Rural. <http://www.agrov.com/vegetais/raizes>. Acesso em 17/09/2010. 


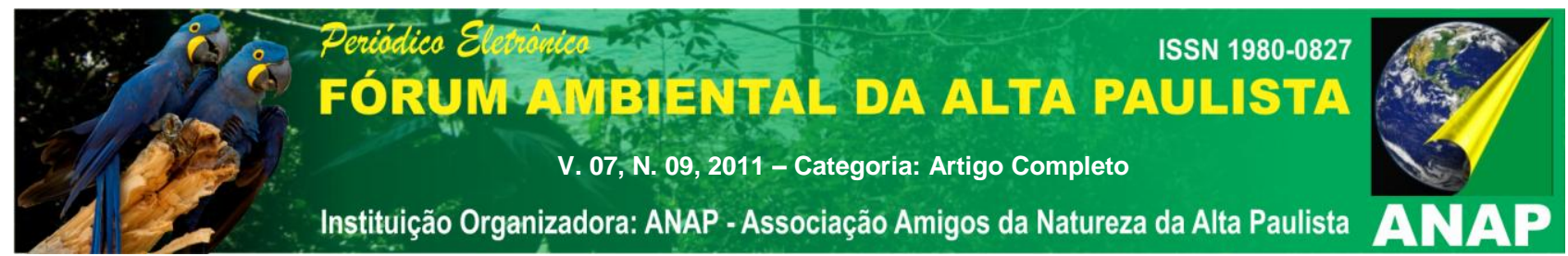

ANAIS DE VILA BELA 1734-1789/ Janaína Amaro, Leny CaselliAnzai, organizadoras; revisão e notas Luiz Carlos Figueiredo; prefácio Paulo Pitaluga Costa e Silva. Cuiabá: Carlini\&Caniato: EdUFMT, 2006.

BANDEIRA, Maria de Lourdes; FREIRE, Otávio. Antropologia - Três categorias do pensamento antropológico. Cuiabá: EdUFMT, 2006.

BRASIL, Ministério da Educação. Secretaria da Educação e Tecnologia. Parâmetros Curriculares Nacionais do Ensino Médio. Brasília, 2000.

BRITO, Luciana da Cruz. Tópicos sobre a historia do negro na sociedade brasileira. Cuiabá: EdUFMT, 2011.

COLÉGIO SÃO FRANCISCO. Alimentos Vegetais. Acesso em 17/09/2010 $<$ http://www.portalsaofrancisco.com.br>

FERREIRA, João Carlos Vicente. Mato Grosso e Seus Municípios/ João Carlos Vicente Ferreira. Cuiabá: Secretaria de estado da Educação, 2001.

FIRMO, Yandra. As relações raciais e diversidade no cotidiano escolar. Estratégias de combate ao racismo / Edenar Monteiro, Ivone Jesus Alexandre, Yandra Firmo, Maristela Abadia Guimarães, Maria Lúcia Rodrigues Müller (org.). Cuiabá: EdUFMT, 2010.

Revista Ervas \& Saúde. Ano II, № 3. São Paulo: Escala LTDA. 1998.

SANTOS, Ângela Maria dos. Identidade e Cultura Afro-Brasileira. 2.ed./ Ângela Maria dos Santos, Maria Lúcia Rodrigues Müller (org.). Cuiabá: EdUFMT, 2010.

SILVA FILHO, José Barbosa da. Apontamentos Sobre a História do Negro no Brasil. 2.ed./ José Barbosa da Silva Filho, Maria Lúcia Rodrigues Müller (org.). Cuiabá: EdUFMT, 2010. 